\title{
The Effects of the Use of a Conversational Model and Opportunities for Reflection in Computer-Based Role-Playing
}

\author{
Geralien A. Holsbrink-Engels \\ Department of Instructional Technology, \\ University of Twente
}

\begin{abstract}
This study examined the effects of an instructional program on 21year-old students' interpersonal skills development $(\mathrm{N}=104)$. The HyperCard 2.1 program "Telling bad news" could contain a conversational model that informed students about the main moments and actions in conducting a bad-news conversation. In addition, the program could vary the students' opportunities for reflection by slowing down the dialog. It was expected that the conversationalmodel-present groups and the high reflection groups would show more effective interpersonal skill acquisition, knowledge acquisition, and a more complete understanding of the skill (better tests results) than the conversational-modelabsent groups and the low reflection groups. Both elements were found to affect the students' interpersonal skill development. The presence of a conversational model significantly improved the students' role-play, $\mathrm{F}(1,94)=8.79, \mathrm{p}<.01$, and their performance on the knowledge test, $\mathrm{F}(1,94)=115.28, \mathrm{p}<.001$. When also given opportunities for reflection, the students' performance in a roleplay and on the knowledge test improved even more, $\mathrm{F}(4,91)=2.69, \mathrm{p}<.05$. The instruction program with the presence of a conversational model in combination with opportunities for reflection is, therefore, considered as having
\end{abstract}

Requests for reprints should be addressed to Geralien A. Holsbrink-Engels, University of Twente, Department of Instructional Technology, P.O. Box 217, 7500 AE Enschede, The Netherlands. E-mail: holsbrink@edte.utwente.nl 
the potential to assist in realizing effective gradual lead into interpersonal skills learning and instruction for novices. (1) 1997 Elsevier Science Ltd

In recent years, the role of technology for realizing effective interpersonal skills development has received increased attention from educational technologists. For example, it is possible to build a guided social simulation, a simulated social world, in which social skills can be practiced (Kass, Burke, Blevis, \& Williamson, 1993-1994). The main question is how advisable is it to realize effective interpersonal skills development by support of technology. Studies conducted to investigate this have reported benefits for students and staff. Students benefit from increasing performance when technology is used (Alliger, Serbell, \& Vadas, 1989; Alpert, 1986; Campbell, Lison, Borsook, Hoover, \& Arnold, 1995; Schroeder, Dyer, Czerny, Youngling, \& Gillotti, 1986 ) and benefit from a saving of $20-30 \%$ in learning time (Orlansky \& String, 1977; Fletcher, 1990). Staff benefit from a saving of $50-67 \%$ in instructor time (Campbell et al., 1995) and saving $100 \%$ branch personnel time (Alliger et al., 1989).

Despite these benefits, research on support of technology to realize effective interpersonal skills development can be characterized as limited and hard to conduct, to evaluate performance, and to provide feedback (Campbell et al., 1995). Some researchers have not found a positive significant effect for student performance when technology is used (Martin, Jones, \& Hearn, 1994). Thus, research has provided mixed and divergent results. There appear to be significant instructional benefits, but the absence of a comprehensive theory to explain the results and the methodological weakness of some studies ask for a critical review (Cronin \& Cronin, 1992).

To focus this research problem, the purpose of the current study is to investigate new instructional prospects for interpersonal skills development with the help of a computer-based tool. The study concentrates on interpersonal skills practice in role-plays, an important part of interpersonal skills training designs (Baker \& Daniels, 1989; Goldstein, 1973, 1981; Hollin \& Trower, 1986; Ivey, 1971; Ivey \& Authier, 1978; L'Abate \& Milan, 1985; Marshall \& Kurtz, 1982). Interpersonal skills are seen as skills to deal with interactive processes involved in a dyadic (two-person) interaction (Hargie, 1986). They are seen as ill-defined skills in which hard-and-fast principles are lacking and a heuristic rule of thumb must be relied on (Kass et al., 1993-1994). Role-playing is seen as an instructional method in which students play a situation from reality. The situation concerns a dyadic interaction with a goal. A specification of variables in role-playing based on a literature review is given by Holsbrink-Engels (1994). 
For novices, a conventional role-play is a very complex learning situation. In particular, the stage of "running the role-play" is (too) complex for beginners because they must pay attention to verbal and nonverbal aspects of the conversation and in addition have to control emotions and deal with "pace" of the exchange. There is little or no time to reflect on the main moments and actions in conducting a conversation. For novices, a role-play may also fail to build the intended skills due to a lack of repeated exposures (Georges, 1989), and due to the fact that students cannot keep track of what is learned and the order in which it is learned (Van Ments, 1989). Computerbased role-playing is designed to simplify role-playing so that students can more effectively develop interpersonal skills. It is a graduate lead into, not a replacement of, conventional role-playing (Holsbrink-Engels, in press).

Within computer-based role-playing, the effects of two instructional principles, the use of a conversational model and opportunities for reflection, on learning outcomes, learning processes, and appreciation of the training are studied.

The first instructional principle under study is the use of a conversational model. In a conversational model, a heuristic sequence and content of actions is described that characterizes an optimal approach to solve interpersonal problems. Based on a specification of the actions and methods that ensure a systematic approach to problem solving (SAP-analysis, one possible approach to analyze ill-defined skills; Mettes, Pilot, \& Roossink, 1981), a heuristic procedure is formulated to model performance of the skill. For instance, the conversational model of the interpersonal skill "telling bad news" used in the current study is as follows. To tell bad news, the student must

1. Tell the bad news straight after a short introduction

- STOP: wait for the receiver's reaction

2. Listen and reduce frustration

- by reflections

- repeat the bad news

3. Give necessary background information

4. Listen and reduce frustration again

5. Try problem solving

6. Stick to a concrete agreement

With regard to the teaching of heuristics, most researchers agree that it is helpful to present heuristics to students (Mettes et al., 1981; Schoenfeld, 1979). Researchers have indicated that the presentation of heuristics primarily focuses on the prior availability of this information in memory in such a way that it is highly integrated with knowledge that already exists. 
This increases the chance that the information can be helpful to the performance of the skills (Van Merriënboer, Jelsma, \& Paas, 1992). Theorists who are primarily concerned with giving guidance in problem-solving situations have suggested that guidance should be used to aid the novice in developing an expert's awareness of problem space in which problem solving takes place. Teaching students problem space representational skills may be the most effective way to turn a "poor" novice problem solver into a "good" novice problem solver, thereby facilitating the development of expertise (Redding, 1990).

The second instructional principle under study is opportunities for reflection. Reflection is seen as an essential part of the learning process (Dewey, 1933; Hatton \& Smith, 1995). Reflection refers to the possibility to consider the chosen personal approach of the conversation problem. Completing tasks and solving problems is a necessary but not sufficient condition for learning. Adult students must be encouraged to reflect. In the process of reflection, schemes of schemes are constructed (Wheatley, 1992). This thought process involves active chaining (Kremer-Hayon, 1988; SparksLanger \& Colton, 1991; Waxman, Freiberg, Vaughan, \& Weil, 1988), and careful ordering of interconnected ideas which take into account underlying beliefs and knowledge (Dewey, 1933). Adult students who reflect have greater control over their thinking and can decide which of several paths to take, rather than simply taking action. It is possible that adult students may be so active that they fail to reflect and, thus, do not learn.

More recently, it has been suggested that it may be fruitful to "build in" further opportunities for reflection which involve simultaneous reflecting and doing. The process of "reflection-in-action" (Schön, 1983, 1987) may be a key mechanism in learning (Boud \& Walker, 1991). Most kinds of reflections in role-play theories involve looking back upon action some time after it has taken place (Joyce \& Weil, 1980; Kessels \& Smit, 1990; Nijkerk, 1988; Van Ments, 1989). During role-playing there is no time for reflection because students experience a forward push to the next element of the exchange. Winograd and Flores (1986) call this characteristic of real-life dialog "thrownness". The students are not able to think consciously about what is taking place and modify actions virtually instantaneously. With the help of a computer-based tool, the possibility of reflection-in-action during roleplaying is offered. Computer-based role-playing offers a design-throughdialog process which exhibits thrownness, slow enough for reflection on the exchange to be effective but fast enough to keep the conversation going.

The current study was conducted to determine the effects of the use of a conversational model and opportunities for reflection in a computer-based training program for role-playing. According to the line of reasoning, it was expected that the conversational-model-present groups would show more 
effective interpersonal skill acquisition, knowledge acquisition, and a more complete understanding of the skill (better tests results) than the conversational-model-absent groups. In addition, it was hypothesized that students in the high reflection groups would show more effective interpersonal skill acquisition, knowledge acquisition, and a more complete understanding of the interpersonal skill (better tests results) than students in the low reflection groups. There were no specific expectations with regard to the interaction between the conversational model and the reflection opportunities variables. These hypotheses and several learning processes were investigated in this study.

\section{METHOD}

\section{Design and Subjects}

In the current study, variations in computer-based role-playing were made. A $2 \times 2$ factorial design was used, with conversational model (present, $\mathrm{C}^{+}$, vs. absent, $\mathrm{C}^{-}$) and reflection opportunities (high, $\mathrm{R}^{+}$, vs. low, $\mathrm{R}^{-}$) as independent variables. The dependent variables were learning outcomes, learning processes, and appreciation of the training.

Subjects were 120 students (67 females and 53 males) and 5 substitute students ( 3 females and 2 males, explained later) from the University of Twente with a mean age of 21 years. Students were stratified by gender to insure proportional representation and randomly assigned to groups of two in one of four instructional treatments $\left(\mathrm{R}^{+} \mathrm{C}^{+}=30,17\right.$ females and 13 males; $R^{+} C^{-}=30,17$ females and 13 males; $R^{-} C^{+}=30,17$ females and 13 males; $\mathrm{R}^{-} \mathrm{C}^{-}=30,16$ females and 14 males) and tested individually. The students were paid for their participation in the experiment (30 Dutch guilders, approximately $\$ 18$ ).

\section{Experimental Conditions}

Experimental conditions constituted in this study were four types of interpersonal skills training programs with computer-based role-playing. All training programs included a set of four interpersonal problems which were identical in each training. The problems provided different real-world conversations to realize variable performance. The following interpersonal problems were presented. Tell another person that (a) he/she has been turned down for a trip to Australia, (b) his/her report is rejected, (c) he/she has to accept another (lower) position because of reorganization, and (d) he/she has to accept another (lower) position because of personal disfunctioning. 
The problems had to be solved in a computer-based role-play. Computerbased role-playing took place on two physically separated but connected computers. The dialog between the students occurred through typewritten text in conversation bubbles on the computer screen (Figure 1d). The communication messages are exchanged by a Local Talk network after clicking on a send button.

For each role-play the following six stages occurred: (a) an introductory computer-screen with a picture of the building where the conversation should take place; (b) a text-screen with a description of the social situation; (c) a text-screen with a description of the role; (d) a dialog-screen for role-playing (typing and reading messages); (e) a print-screen to make a printout of the dialog, and (f) debrief the dialog by the printout. After finishing Role-Play 1, the same six stages occurred for Role-Play 2 and so forth. Figure 1 shows an example of a presented problem.

The training program varied with regard to the use of a conversational model and opportunities for reflection. The training principle regarding the use of a conversational model indicates that instruction should offer practice in the solving of interpersonal problems under guidance of a conversational model. The training principle regarding opportunities for reflection indicates that instruction should offer students enough time to consider their actions by conscious use of analytical reasoning and planning.

The use of a conversational model was realized in two ways. First, before role-playing each student studied a paper that described the interpersonal skill either with or without a conversational model. The papers were otherwise identical. Second, during computer-based role-playing, the conversational model was either in view at all times and shown next to the current section the student was working on or was absent.

Opportunities for reflection were realized in several ways. Students can revise each message (delete and make corrections) and determine when the next message is exchanged (no or less pressure to respond quickly). Further, it is possible to read back the dialog, the descriptions of the social situation, and the description of the role. Students can answer questions on the application of the conversational model (reflection-stimulating questionnaire before "running the computer-based role-play") and their performances (reflection-stimulating questionnaire after "running the computer-based roleplay").

To sum up, variations in the materials occurred in the papers and in the computer-based role-plays. These variations were based on the training principle (conversational model and reflection opportunities) under study. Figure 2 shows the variation (in detail) in the four training programs. 


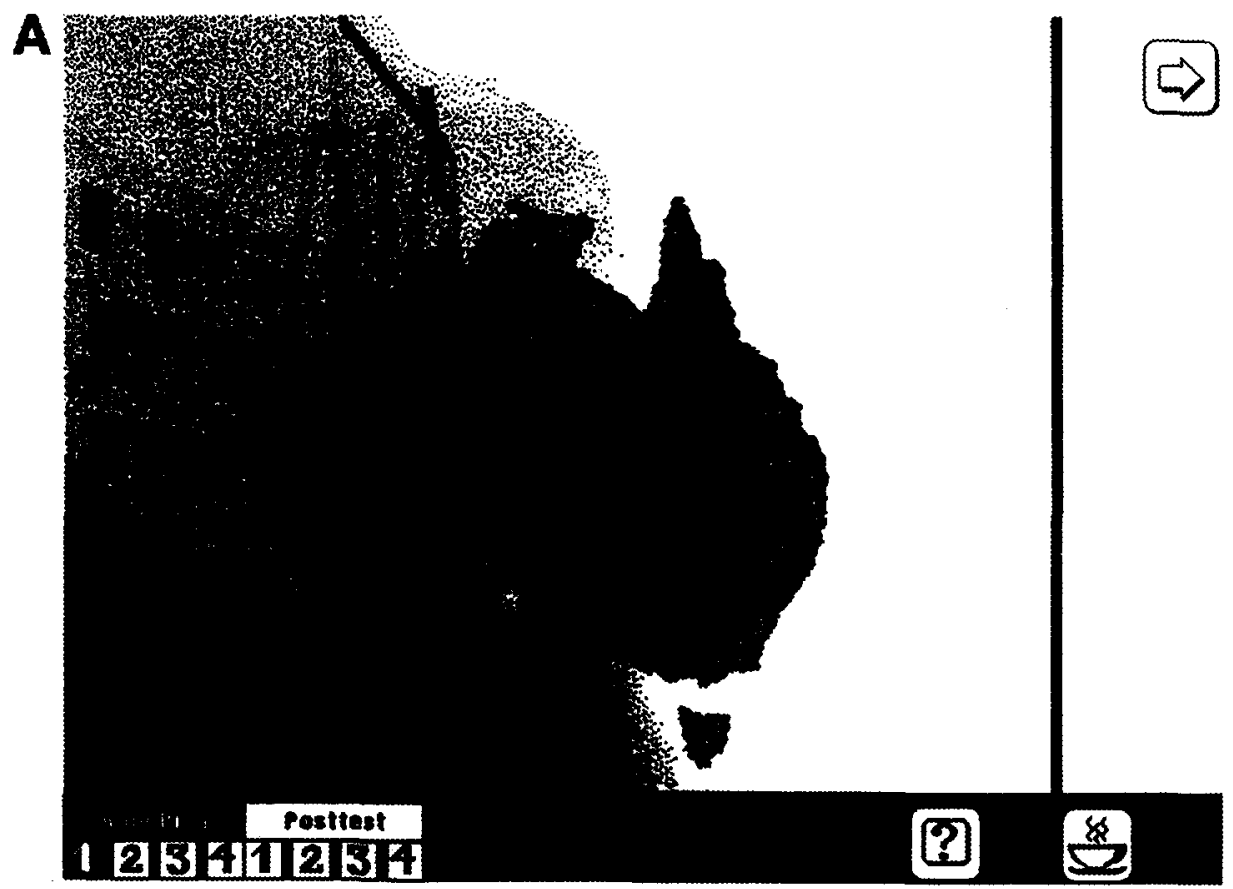

B

Description of the social situation

Every two years, the Faculty of Educational Science and

Technology (the University of Twente) organizes a student exchange program. This year, the exchange takes place between Australian and Dutch students. A selection committee organizes the exchange.

Role list

D. Stuart, assistant professor and chair of the selection committee, 35 years.

M. VanTol, student, 22 years.

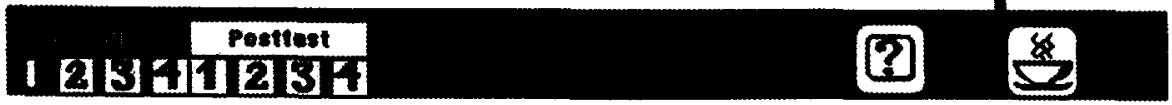

Figure 1. First practice interpersonal problem of all treatment groups. 


\section{C}

\section{Role description}

You are D. Stuart, chair of the selection committee and one of the initiators of the student exchange program with Australia.

From the Dutch are 50 students interested. From the

Australians only 10 students show an interest in exchange. For this reason and for reasons of offering enough accomodation to the students, only 10 Dutch students are allowed to visit Australia. The 10 'lucky' students are selected by drawing lots. You have to tell one of the students with high expectations that he/she is eliminated by lottery. It is absolutely impossible that the student will have an opportunity to visit Australia. He/she is also not selected for a substitule place.

\section{Task}

You tell the bad news to VanTol in a personal talk.
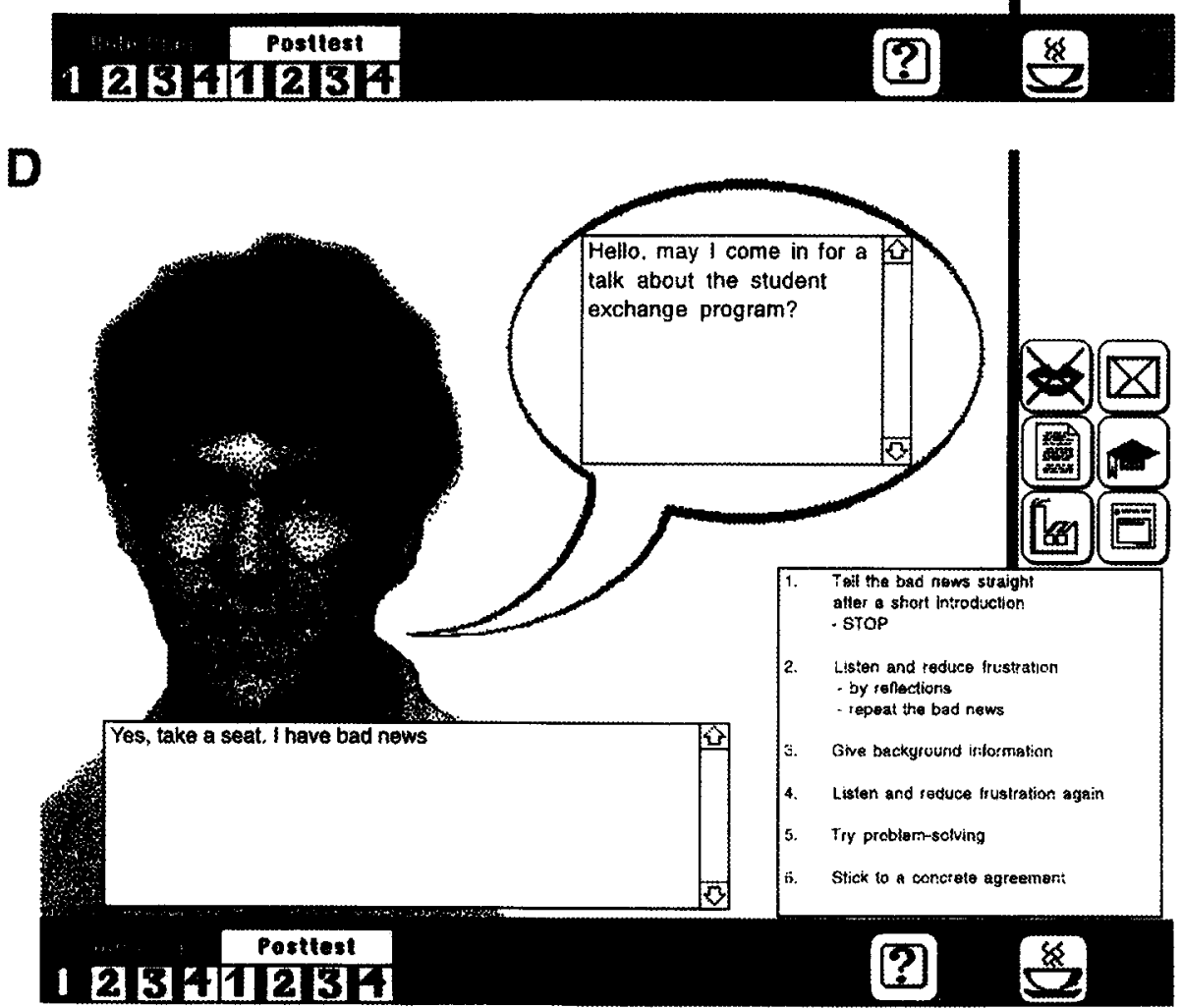

Figure 1. Continued. 
The four training programs were developed using HyperCard 2.1 on a Macintosh II and LC computer. The programs were developed on a screen of $640 \times 480$ pixels with no use of color.

\section{Measures}

There were three dependent measures used in this study. These measures included learning outcomes, learning processes, and appreciation of the training program. A registration program was installed on each computer. It stored the students' actions, starting and ending times by program sections in a logfile. The logfile of each student was printed and so available for data analysis.

\section{CONVERSATIONAL MODEL}
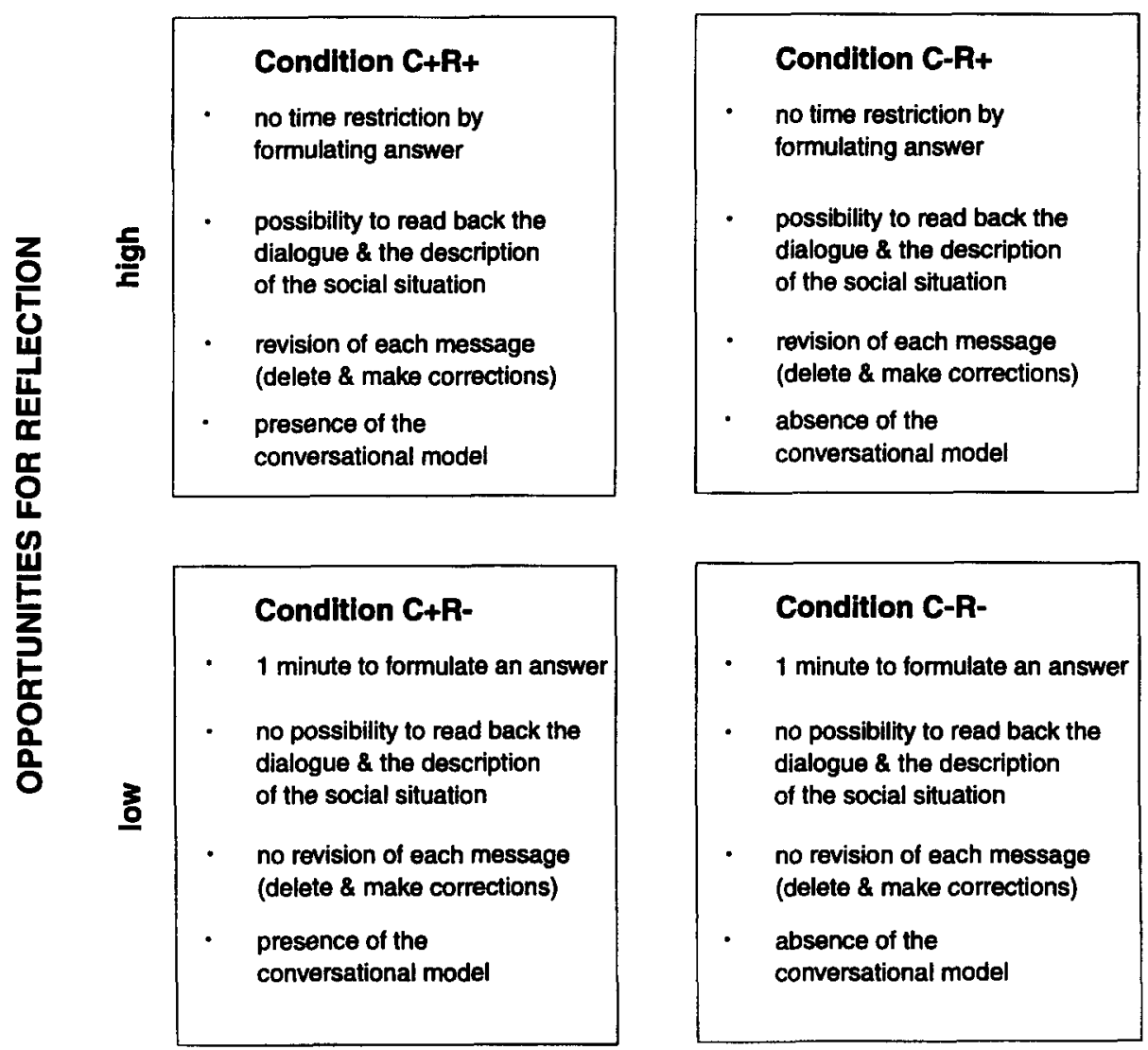

Figure 2. The variation in the four training programs in detall. 
Learning outcomes . Learning outcomes were measured using four computerbased posttests with logfile registration. The first posttest was performed by groups of two and the other three posttests were performed individually. One person scored all of the items on these last three tests.

The first posttest, the performance in a computer-based role-play, consisted of two interpersonal problems. The problems were to tell another person that he/she (a) has to move from The Hague to Maastricht to keep his/her job and (b) has to move to Atlanta for a year to keep his/her position. The students played once a protagonist and once an antagonist role. The two problems were counter-balanced, so that half of each group received problem (a) and the other half problem (b).

Prior to the experiment, a coding plan was developed based on the technique of protocol analysis (Ericsson \& Simon, 1980, 1984; Nisbett \& DeCamp Wilson, 1977) and the Maastricht History-Taking and Advice Checklist (Kraan \& Crijnen, 1987). The coding plan consisted of 15 dichotomy items concerning the presence or absence of concrete typed messages in the printouts of the dialog. An item was for instance, "Announces the bad news after a short introduction: yes or no". Scores on 15 items were added together for each student, so the maximum possible score obtainable on the conversation test was 15 . High scores represented high conversation skills. Two interpersonal skills trainers "blindly" assessed the printouts of the dialogs; they did not know which printout belonged to which group. The two raters worked independently. Reliability of judgment was based on both raters having similar totals for performance of each student in computer-based role-playing. The inter-rater reliability (kappa) was .83 .

The second posttest, the knowledge test, contained six open questions about essential characteristics of the interpersonal skill. For instance, "Although the variability of reactions on bad news is large, it is possible to give an enumeration of the most described behaviors. Which are these? Name three. Give the answers and click on OK". The individual answers to each item were checked against a scoring key and points were assigned for each correct response. An item was worth 1 point unless it required a multiple response. For example, the item given above was worth a maximum of 3 points; it was scored by providing 1 point for each described behavior listed in the student's response. The maximum possible score obtainable on the knowledge test was 15 . The Cronbach's internal consistency reliability of the scale was .69 for subjects in the present study.

The third posttest, a classification test, consisted of 10 yes-no questions. The students had to classify whether a conversation is a bad-news conversation or not (e.g., "Els expects to make an enjoyable business trip to Mexico. It is decided that her colleague will take this trip. You tell Els. In 
the case of a bad news-conversation, click on yes. In the case of another conversation-type, click on no."). The answers to each item were checked against a scoring key and 1 point was assigned for each correct response. The maximum possible score, the sum across the 10 items, obtainable on the classification test was 10 . The Cronbach's internal consistency reliability of the scale was .73 for subjects in the present study.

The fourth posttest, a conversation-sequence test, contained an interpersonal problem. The problem was to tell another person to stay in Bolivia instead of returning to the Netherlands to keep his/her job. This test asked students to place six pronounced sentences of the protagonist in a right conversation sequence. The number of sentences each sentence correctly proceeded was counted. One of the 15 items was for instance, "Are the sentences six-four-two correctly ordered?". Each item was worth 1 point. So, the maximum possible score obtainable on the conversation-sequence test was 15 . The Cronbach's internal consistency reliability of the scale was .79 for subjects in the present study.

The typing test was an existing test from a temp agency. This test asked the students to type over a letter. The letter and the time were registered in a logfile. For each student, the typing tempo was expressed in the number of touches per minute.

Learning processes. The description of the learning processes was split up for activity level and time spent on different activities. For activity level, the logfile registration program was assigned to count for each role-play: (a) the number of messages sent by the protagonist, (b) the total number of words used by the protagonist, (c) the frequency of consultation of the description of the social situation and the description of the role, (d) the frequency of consultation of theory, and (e) the frequency of the use of reflectionstimulating questionnaires. For time spent on different activities, the logfile registration program was assigned to index the starting and ending times of: (a) performances in computer-based role-plays, (b) consultation of the description of the social situation and the description of the role, (c) consultation of theory, and (d) the use of reflection-stimulating questionnaires. The starting time subtracted from the ending time was the time spent. The sum of each dependent variable (in practice Role-Plays 1-4) was counted and divided by the number of practice role-plays (4). So, the description of learning processes was based on calculation of the average "activity" and average "time" variables for the practice phase. The average of each dependent variable was taken into account for reasons of central tendency (to avoid fluctuations of chance).

Appreciation questionnaire. A questionnaire assessed students' appreciation of the quality of the training program. The students passed judgment on 33 
quality items on a 5-point satisfied-dissatisfied scale $(1=$ very satisfied, $2=$ satisfied, $3=$ neutral, $4=$ dissatisfied, $5=$ very dissatisfied). A final judgment ( 1 item: "my judgment about the total program is") and three aspects of quality (Carol \& Rosson, 1984, the effectiveness, 12 items; the usefulness, 2 items; and the manageability, 18 items) were considered. The effectiveness relates to the quality and the extension of the manual, the information, the subject matter, and the evaluative feedback. For instance, "How satisfied are you with the step-size of the subject-matter?". The usefulness pertains to the motivational effects and the suitability of the computer-based program in interpersonal skills training for novices. For instance, "How satisfied are you with the way you learn to conduct a badnews conversation through this program?". The manageability is focused on the way students handle the program. For instance, "How satisfied are you with the clearness of the choice-menu and commands?". There was also an opportunity to formulate suggestions for refinements of the training. The Cronbach's internal consistency reliability of the scale was .88 for subjects in the present study.

\section{Procedure}

In a mailing to all first year students from the University of Twente, students were asked to participate in social and management skills training and earn 30 Dutch guilders before the holidays. At the beginning of each session students were told about the task "telling bad news", about the procedure of the experiment, and about computer-based role-playing and were asked to read the paper (three pages) about the skill (total approximately $20 \mathrm{~min}$ in a classroom). The paper was different for half of the groups, depending on assignment to one of the two conversational model groups (present or absent). They were told to raise their hands when they were ready to begin the videotape. When all students indicated that they were ready, two video examples were presented (the skill was demonstrated by an existing videotape with a bad and a good conversation example, approximately $10 \mathrm{~min}$ in a classroom).

After the video presentation, the students were randomly assigned to groups of two, received a computer number and an audio-room number. They were told to go to the computer class. When they arrived they were told to sit at the computer that corresponded with their computer number. The computer class was equipped with a network of 10 (5 groups of 2) Macintosh personal computers. Next to the computer, the students found an explanation sheet (two pages) which provided an introduction to computer-based role-playing and the functions of the buttons on the screen. The explanation sheet was different for each group. The couples were told to start 
the computer program by mouse clicks, to work in their own way and at their own pace. They played the first practice role-play. After completing the first role-play, they made a printout of the dialog and were told to go to the audio-room that corresponded with their audio-room number. They were told to start the tape recorder and record their conversation during the debriefing of the dialog on the basis of the printout. Similar procedures were followed for the other three practice role-plays.

Each student performed the protagonist (the main character) and the antagonist role (the "significant other" who provides resistance; Van Ments, 1989) twice in balanced order. The elements of computer-based role-playing were different, depending on assignment to one of the four groups. The students spent approximately $2.5 \mathrm{hr}$ in the computer class and the audio rooms.

After all four computer-based role-plays were practiced, the students completed four posttests and a typing test (approximately $1 \mathrm{hr}$ in a computer room). The students worked in groups of two on the first test and individually on the three other tests and the typing test. Finally, the students completed the appreciation questionnaire. The students were paid after handing in the questionnaire.

All procedures were identical for the four groups. The experiment consisted of 12 sessions of 6-10 students and the same experimenter conducted all sessions. The conditions were randomly assigned to the sessions.

\section{Data Analysis}

A 2 (conversational model present vs. absent) $\times 2$ (reflection opportunities high vs. low) multivariate analysis of variance (MANOVA) was used to analyze the data concerning learning outcomes, learning processes, and appreciation. If significant, MANOVA was followed by univariate analyses on the $\mathbf{C}, \mathbf{R}$ and sex portions of those data. Correlation and regression analyses were used to determine whether the typing tempo expressed in the number of touches per minute (independent variable) had an effect on the time spent on conversations and posttests (dependent variables). Alpha was set at .05 for these statistical tests.

\section{RESULTS}

The dependent variables were learning outcomes, learning processes, and appreciation of the training. Because of experimental loss (21 subjects completed with 5 substitute subjects), there were no data from 16 subjects. 
This resulted in a sample of 104 students (57 females and 47 males); 30 students in the $\mathrm{R}^{+} \mathrm{C}^{+}$group (17 females and 13 males), 24 students in the $\mathrm{R}^{+} \mathrm{C}^{-}$group (14 females and 10 males), 26 students in the $\mathrm{R}^{-} \mathrm{C}^{+}$group (16 females and 10 males), and 24 students in the $\mathrm{R}^{-} \mathrm{C}^{-}$group (10 females and 14 males).

\section{Learning Outcomes}

The mean scores for the learning outcomes are displayed in Figure 3.

MANOVA revealed a significant interaction between conversational model and reflection opportunities, $F(4,91)=2.69, p<.05$. Univariate analyses revealed that the interaction was significant for the knowledge test of the learning outcomes, $F(1,94)=9.55, p<.01$. As shown in Figure 4, in the $\mathrm{C}^{+}$condition, students receiving the $\mathrm{R}^{+}$treatment attained more knowledge from the training program than the $\mathrm{R}^{-}$treatment. In the $\mathrm{C}^{-}$ condition, there were no apparent differences in knowledge acquisition when the $\mathrm{R}^{+}$and $\mathrm{R}^{-}$treatments were compared.

Scheffe multiple comparison tests revealed that students in the $\mathrm{C}^{+} \mathrm{R}^{+}$ group $(M=10.9)$ and students in the $\mathrm{C}^{+} \mathrm{R}^{-}$group $(M=9.8)$ obtained significantly more knowledge than those in the $\mathrm{C}^{-} \mathrm{R}^{+}$group $(M=5.7)$ and in the $\mathrm{C}^{-} \mathrm{R}^{-}$group $(M=6.5)$. No other differences were found.

In addition to the interaction, MANOVA indicated a significant main effect for conversational model, $F(4,91)=29.38, p<.001$. Univariate analyses revealed that the main effect was significant for two tests of the learning outcomes; performance in a computer-based role-play, $F(1,94)=8.79, p<.01$ and the knowledge test, $F(1,94)=115.28$, $p<.001$. Students in the $\mathrm{C}^{+}$groups $(M=9.8)$ performed significantly better in a computer-based role-play than the $\mathrm{C}^{-}$groups $(M=8.6)$. Also on the knowledge test, students in the $\mathrm{C}^{+}$groups $(M=10.3)$ performed significantly better than students in the $\mathrm{C}^{-}$groups $(M=6.1)$.

MANOVA indicated another significant main effect for sex, $F(4,91)=3.31, p<.01$. Univariate analyses revealed that the main effect was significant for two tests of the learning outcomes; performance in a computer-based role-play, $F(1,94)=7.26, p<.01$, and the knowledge test, $F(1,94)=6.35, p<.05$. Females $(M=9.7)$ performed significantly better in a computer-based role-play than males $(M=8.7)$. Also on the knowledge test, females $(M=8.9)$ performed significantly better than males $(M=7.7)$. MANOVA did not reveal other interactions ( $C \times \operatorname{Sex}, \mathbf{R} \times \operatorname{Sex}, \mathrm{C} \times \mathbf{R} \times \operatorname{Sex})$ and nor a significant main effect for reflection opportunities was found.

Typing test. No significant effects were found for the typing tempo on the time spent on conversations and posttests. There was no indication of covariation. 


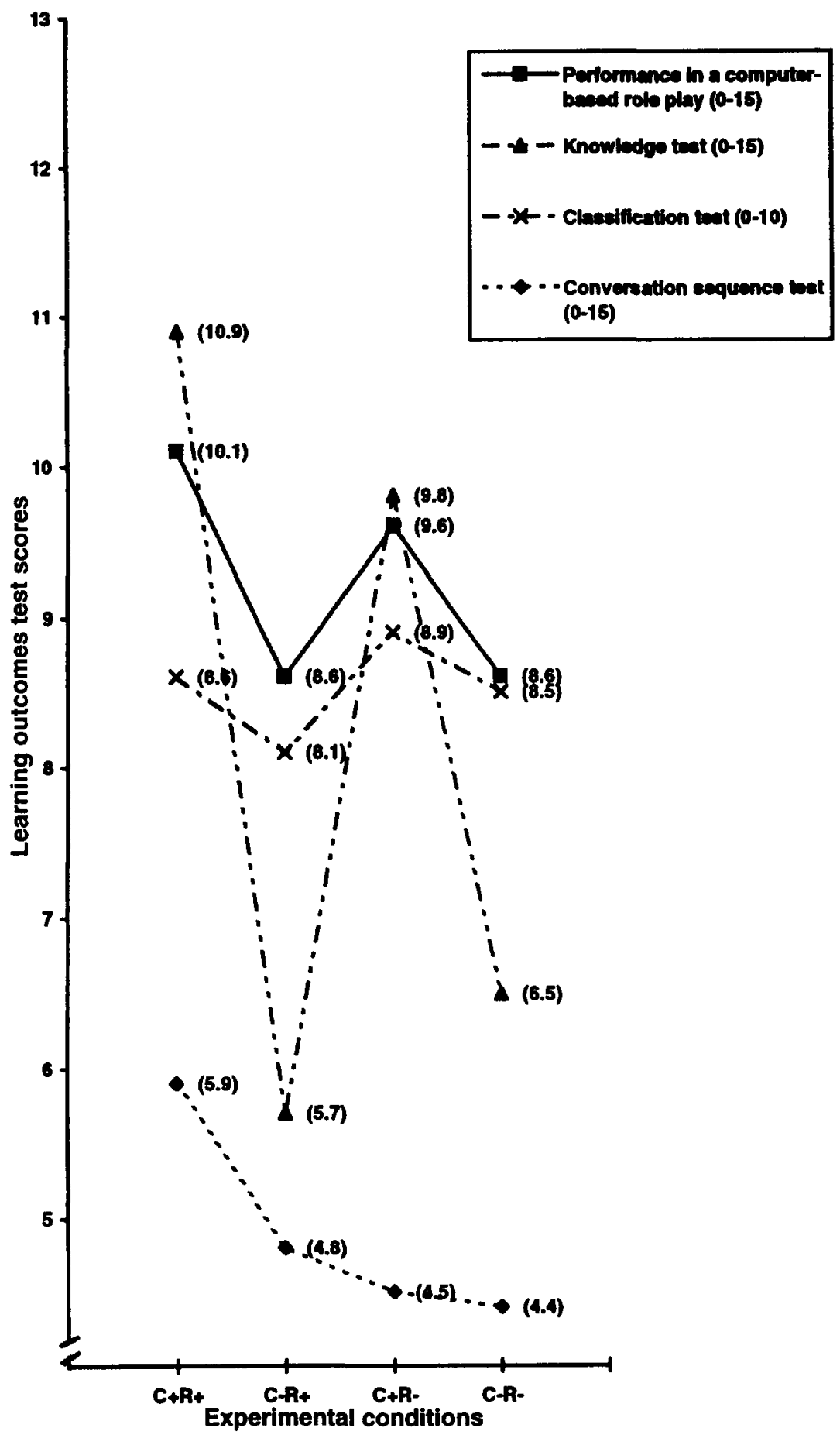

Figure 3. The mean scores for the learning outcomes as a function of the presence or absence of the conversational model and opportunities for reflection. 


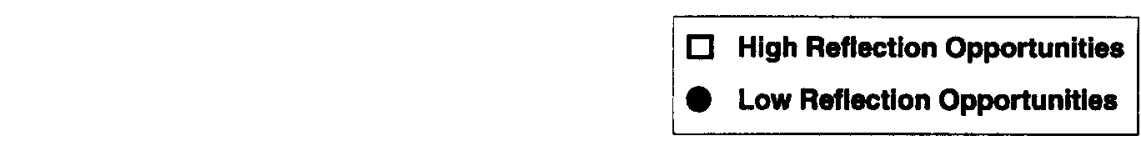

KNOWLEDGE TEST SCORES

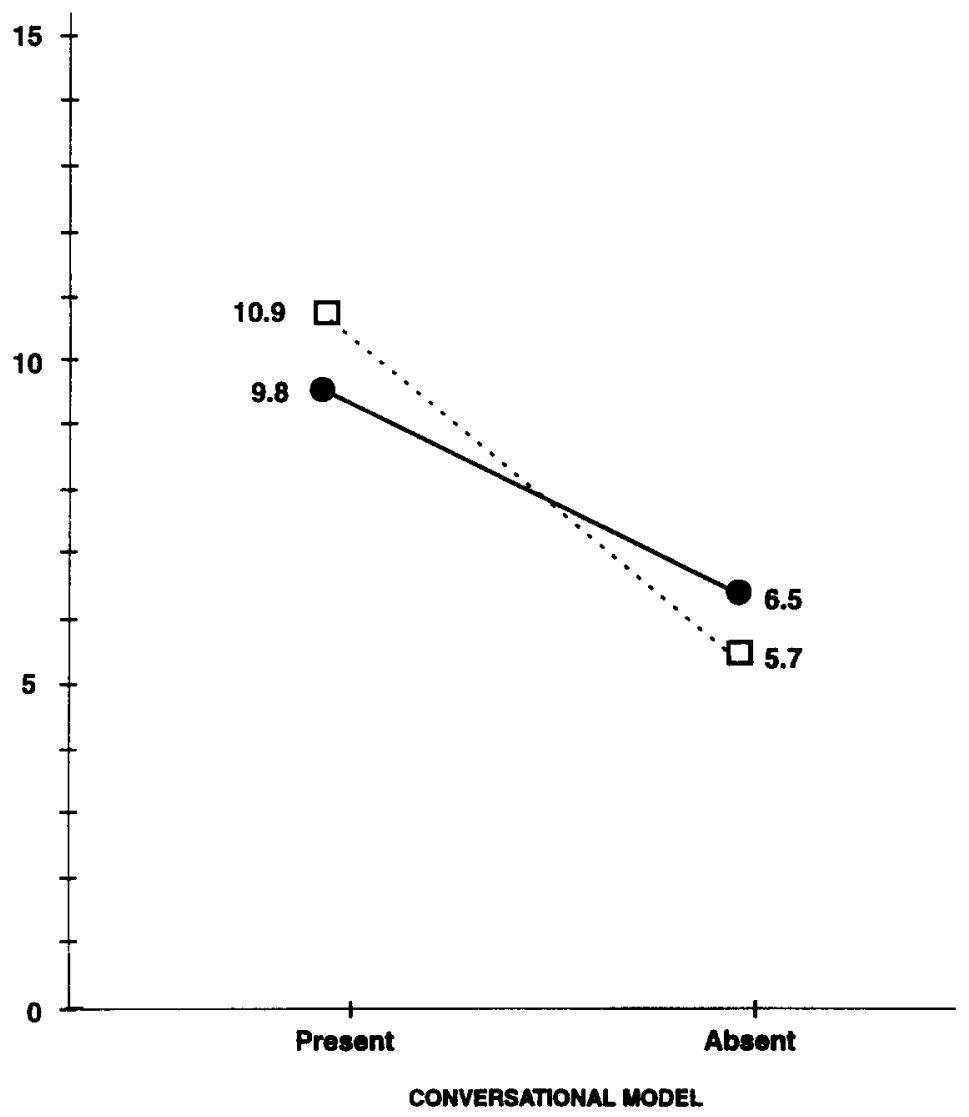

Figure 4. Effects of the presence or absence of the conversational model and opportunities for reflection on the knowledge test scores.

\section{Learning Processes}

The description of the learning processes was split up for activity level and time spent on different activities. The students practiced four computer-based role-plays; two in the role of protagonist and two as antagonist. The analysis of subject data is based on the average of the scores on the two practice roleplays as protagonist. Table 1 shows the mean scores and standard deviations for the learning processes.

Activity level. MANOVA revealed a significant interaction between conversational model and reflection opportunities, $F(3,94)=5.95, p \leq .001$. 
Univariate analyses revealed that the interaction was significant for the average number of messages sent by the protagonist, $F(1,96)=17.42$, $p<.001$. As depicted in Figure 5, students in the $\mathbf{R}^{-}$groups sent more messages when they received $\mathrm{C}^{-}$treatment rather than $\mathrm{C}^{+}$treatment. However, in the $\mathrm{R}^{+}$groups, there was no apparent difference in the number of messages sent when the $\mathrm{C}^{-}$and $\mathrm{C}^{+}$groups were compared.

Scheffé multiple comparison tests revealed that students in the $\mathrm{C}^{-} \mathrm{R}^{-}$ group ( $M=14.0)$ sent significantly more messages than those in the $\mathrm{C}^{+} \mathrm{R}^{-}$ group $(M=11.2)$. Both $\mathrm{R}^{-}$groups sent significantly more messages than those in the $\mathrm{C}^{+} \mathrm{R}^{+}$group $(M=6.7)$, and those in the $\mathrm{C}^{-} \mathrm{R}^{+}$group $(M=6.8)$. No other difference were found.

In addition to the interaction, MANOVA indicated a significant main effect for conversational model, $F(3,94)=5.16, p<.005$ and for reflection opportunities, $F(3,94)=97.45, p<.001$. For the average number of

Table 1. Mean Scores (and Standard Deviations) for the Learning Processes as a Function of the Presence or Absence of the Conversational Model and Opportunities for Reflection

\begin{tabular}{lcccc}
\hline & \multicolumn{4}{c}{ Treatment group } \\
\cline { 2 - 6 } Dependent variables & $\mathrm{C}^{+} \mathrm{R}^{+}$ & $\mathrm{C}^{-} \mathrm{R}^{+}$ & $\mathrm{C}^{+} \mathrm{R}^{-}$ & $\mathrm{C}^{-} \mathrm{R}^{-}$ \\
\hline Activity level (averages) & $\mathrm{a}$ & & & \\
Number of messages & 6.7 & 6.8 & 11.2 & 14.0 \\
& $(1.7)$ & $(1.6)$ & $(1.5)$ & $(2.1)$ \\
Number of used words & 287 & 305 & 281 & 293 \\
& $(62)$ & $(69)$ & $(74)$ & $(88)$ \\
Frequency consultation situation and role & 3.4 & 1.8 & - & - \\
& $(3.0)$ & $(2.2)$ & $(-)$ & $(-)$ \\
Frequency consultation theory & 0.2 & 0.2 & 0.2 & 0.4 \\
& $(0.3)$ & $(0.3)$ & $(0.4)$ & $(0.7)$ \\
Frequency reflection-simulating & 0.1 & 0.3 & - & - \\
questionnaires & $(0.3)$ & $(0.4)$ & $(-)$ & $(-)$ \\
& & & & \\
Time spent on different activities & & & & \\
(averages in minutes) & & & 21.3 & 23.9 \\
Time on performance & 29.5 & 27.6 & 21.9 \\
Time on consultation situation and role & $(6.0)$ & $(3.0)$ & $(4.3)$ & $(4.6)$ \\
Time on consultation theory & 1.0 & 0.5 & - & - \\
Time on reflection-stimulating & $(0.8)$ & $(0.7)$ & $(-)$ & $(-)$ \\
questionnaires & 0.04 & 0.02 & 0.03 & 0.10 \\
& $(0.12)$ & $(0.04)$ & $(0.05)$ & $(0.25)$ \\
\hline
\end{tabular}

Note. - indicates not available because of fixing the variable for the $\mathbf{R}^{-}$groups.

a The average "activity" is presented. The average of the four practice role-plays in the practice phase is stated to measure central tendency (i.e., the sum of the number messages sent during the practice phase divided by the number of practice role-plays (4).

b The average "time spent" is presented. The average time spent on the four practice role-plays in the practice phase is stated (i.e., the sum of the time spent divided by the number of practice roleplays). 


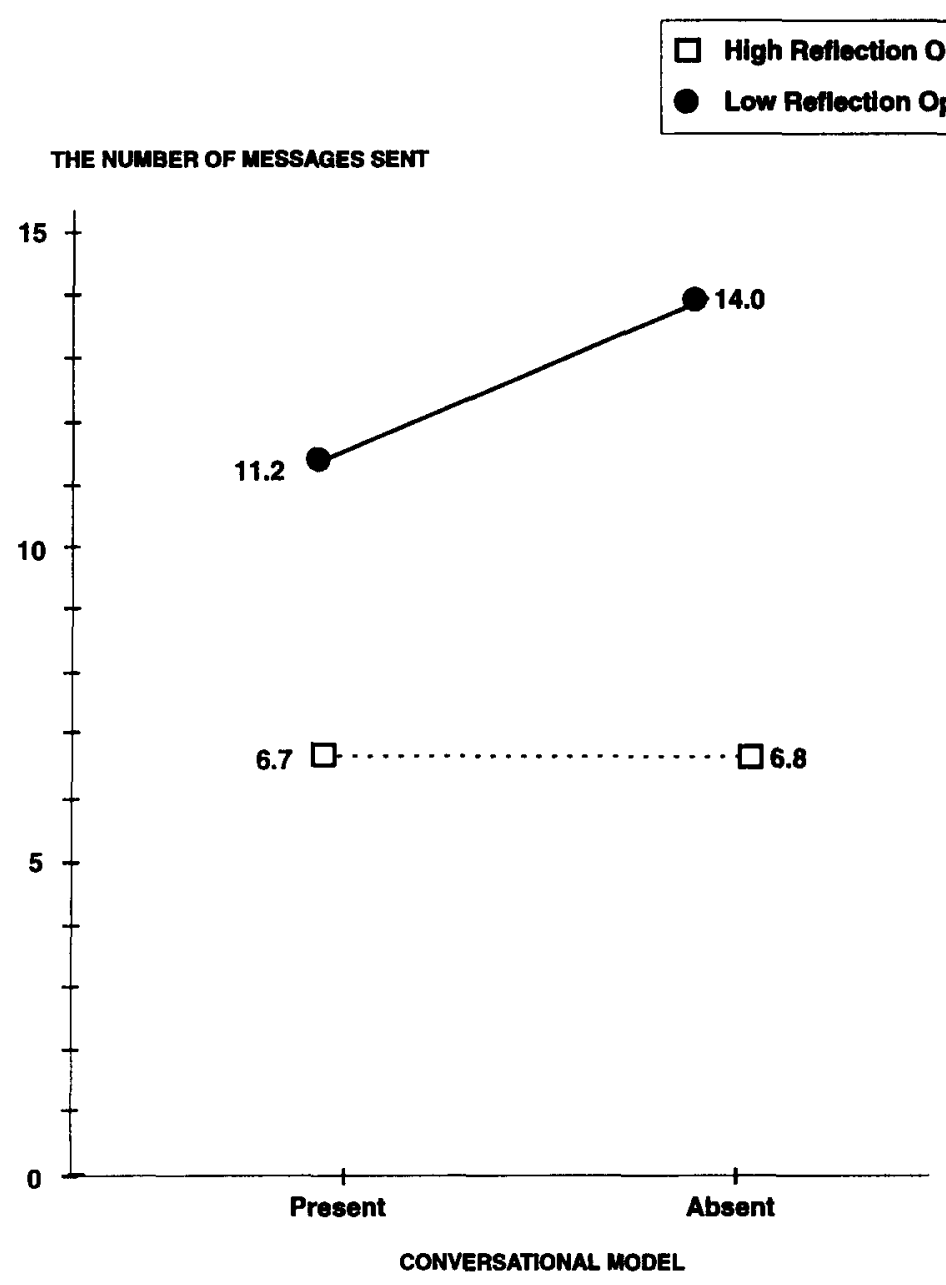

Figure 5. Effects of the presence or absence of the conversational model and opportunities for reflection on the average number of messages sent by the protagonists.

messages sent by the protagonists, ANOVA indicated a significant main effect for conversational model, $F(1,96)=12.58, p \leq .001$, and a significant main effect for reflection opportunities, $F(1,96)=285.55, p<.001$. The $\mathrm{C}^{-}$ groups $(M=10.4)$ sent more messages than the $\mathrm{C}^{+}$groups $(M=8.9)$. The $\mathrm{R}^{-}$groups $(M=12.6)$ sent more messages than the $\mathrm{R}^{+}$groups $(M=6.7)$. MANOVA did not reveal other interactions $(\mathrm{C} \times \mathrm{Sex}, \mathrm{R} \times \mathrm{Sex}, \mathrm{C} \times \mathrm{R} \times \mathrm{Sex})$ nor a significant main effect for sex.

MANOVA was not possible for the variables "frequency consultation situation and role" and "frequency reflection-stimulating questionnaires" 
because of fixing both variables for the $\mathrm{R}^{-}$groups. For $\mathrm{R}^{+}$groups, $t$ tests were used. These $t$ tests revealed a significant difference on the average frequency of consultation, $t(52)=2.14, p<.05$. The $\mathrm{C}^{+}$groups $(M=3.4)$ consulted the description of the social situation and the description of the role significantly more than the $\mathrm{C}^{-}$groups $(M=1.8)$. No other significant differences were found for activity level.

Time spent in different activities. MANOVA revealed a significant interaction between conversational model and reflection opportunities, $F(2,95)=6.37$, $p<.005$. Univariate analyses revealed that the interaction was significant for the average time spent on performance in computer-based role-plays, $F(1,96)=8.71, p<.005$. Figure 6 depicts this significant interaction. In the high reflection mode, students receiving the $\mathrm{C}^{+}$treatment spent more time on performance than the $\mathrm{C}^{-}$groups. However, in the low reflection mode the reverse was true, students in the $\mathrm{C}^{-}$groups spent more time on performance than the $\mathrm{C}^{+}$groups.

Scheffe multiple comparison tests revealed that students in the $\mathrm{C}^{+} \mathrm{R}^{+}$ group $(M=29.5)$ spent significantly more time than those in the $\mathrm{C}^{+} \mathrm{R}^{-}$ group $(M=21.3)$ and those in the $\mathrm{C}^{-} \mathrm{R}^{-}$group $(M=23.9)$. Students in the $\mathrm{C}^{-} \mathrm{R}^{+}$group $(M=27.6)$ spent significantly more time than those in the $\mathrm{C}^{+} \mathrm{R}^{-}$group $(M=21.3)$. No other differences were found.

In addition to the interaction, MANOVA indicated a significant main effect for reflection opportunities, $F(2,95)=21.07, p<.001$ and for sex, $F(2,95)=4.67, p<.05$. Univariate analyses revealed that both main effects were significant for the average time spent on performance in computerbased role-plays. The univariate main effect for reflection opportunities was $F(1,96)=45.32, p<.001$, and for sex was $F(1,96)=4.72, p<.05$. The $\mathrm{R}^{+}$ groups $(M=28.6 \mathrm{~min})$ spent more time on performance in computer-based role-plays than the $\mathrm{R}^{-}$groups $(M=22.6 \mathrm{~min})$ and females $(M=28.6 \mathrm{~min})$ spent more time on performance in computer-based role-plays than males $(M=22.6 \mathrm{~min})$. MANOVA did not reveal other interactions $(\mathrm{C} \times \mathrm{Sex}$, $\mathrm{R} \times$ Sex, $\mathrm{C} \times \mathrm{R} \times$ Sex) nor a significant main effect for conversational model.

For the reason already mentioned, MANOVA was not possible for the variables "time on consultation situation and role" and "time on reflectionstimulating questionnaires". For $\mathrm{R}^{+}$groups, $t$ tests were used. A $t$ test performed on the average time for consultation of the description of the social situation and the description of the role revealed a significant difference, $t(52)=2.00, p<.05$. The $\mathrm{C}^{+}$groups $(M=1.0 \mathrm{~min})$ spent significantly more time on the description of the social situation and role than the $\mathrm{C}^{-}$gtoups $(M=0.5 \mathrm{~min})$. No other significant differences were found for time spent on different activities. 


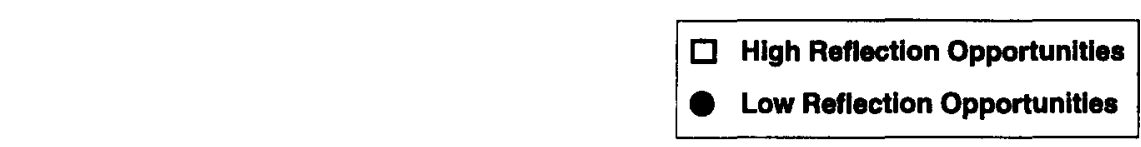

AVERAGE TIME SPENT ON PERFORMANCE (MINUTES)

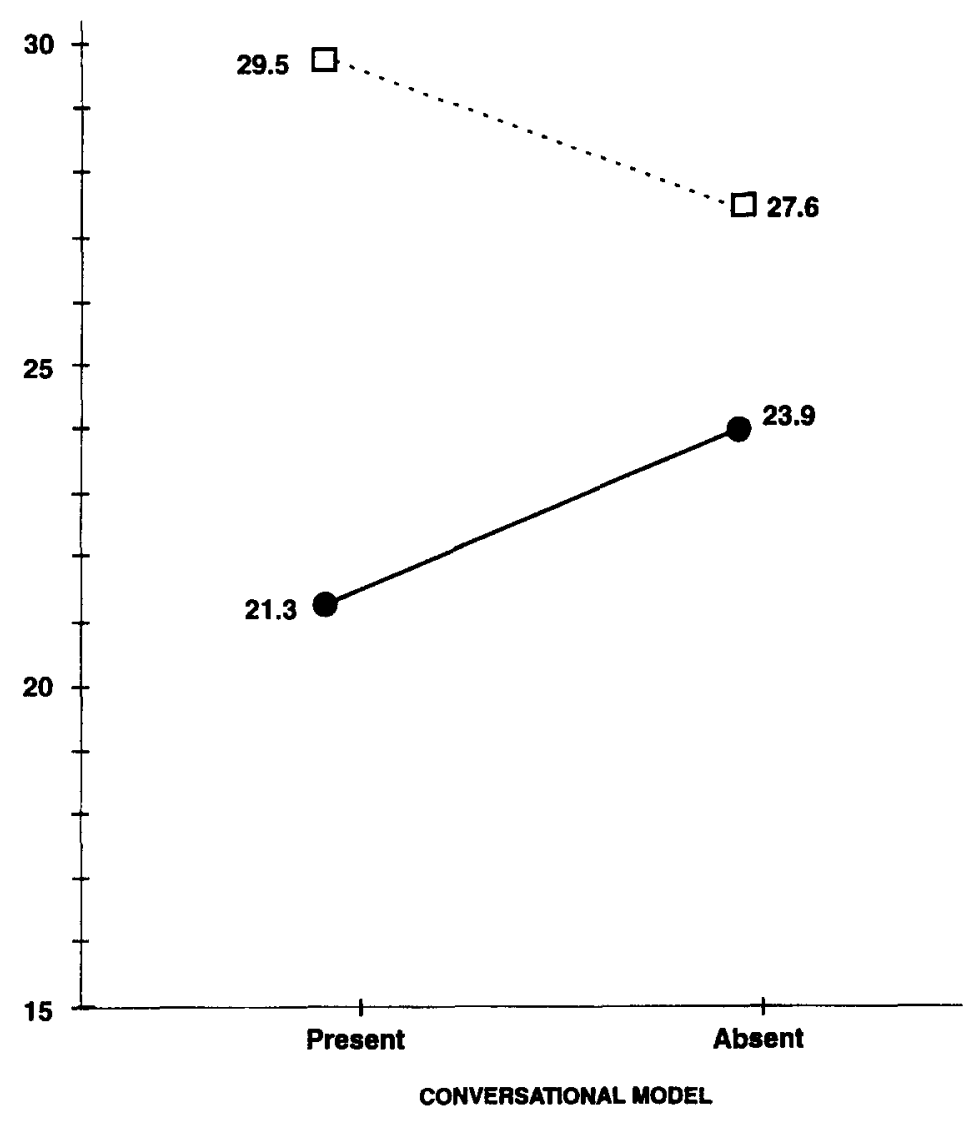

Figure 6. Effects of the presence or absence of the conversational model and opportunitles for refiection on the average time spent on performance.

\section{Appreciation Questionnaire}

Table 2 provides the mean judgment scores of the quality of the training program for the four groups. Data for 101 of the 104 subjects were included in the MANOVA analysis, since 3 subjects did not complete all items of the questionnaire.

MANOVA indicated that sex significantly affected the appreciation of the quality of the training program, $F(4,89)=2.71, p<.05$. Follow-up univariate analyses indicated no significant effect on each of the four portions of the questionnaire, nor any significant effects for the appreciation of the quality. 
Table 2. Mean Judgment Scores (and Standard Deviations) of the Four Groups for the Training Programs

\begin{tabular}{lcccc}
\hline & \multicolumn{4}{c}{ Treatment group } \\
\cline { 2 - 5 } Judgment $^{\mathrm{n}}$ & $\mathrm{C}^{+} \mathrm{R}^{+}$ & $\mathrm{C}^{-} \mathrm{R}^{+}$ & $\mathrm{C}^{+} \mathrm{R}^{-}$ & $\mathrm{C}^{-} \mathrm{R}^{-}$ \\
\hline Effectiveness & 2.4 & 2.3 & 2.3 & 2.7 \\
& $(0.53)$ & $(0.62)$ & $(0.48)$ & $(0.43)$ \\
Usefulness & 2.7 & 3.0 & 2.8 & 2.9 \\
& $(0.82)$ & $(1.10)$ & $(1.00)$ & $(1.00)$ \\
Manageability & 2.2 & 2.1 & 2.4 & 2.4 \\
& $(0.43)$ & $(0.48)$ & $(0.48)$ & $(0.43)$ \\
Final judgment & 2.2 & 2.5 & 2.5 & 2.6 \\
& $(0.77)$ & $(1.10)$ & $(0.95)$ & $(0.99)$ \\
\hline
\end{tabular}

Note. $\mathrm{C}^{+} \mathrm{R}^{+}=$high reflection opportunities, presence of the conversation model; $\mathrm{C}^{-} \mathrm{R}^{+}=$high reflection opportunities, absence of the conversation model; $C^{+} R^{-}=$low reflection opportunities, presence of the conversation model; $\mathrm{C}^{-} \mathrm{R}^{-}$= low reflection opportunities, absence of the conversation model.

${ }_{1}$ = very satisfied, 2 = satisfied, $3=$ neutral, 4 = dissatisfied, 5 = very dissatisfied.

\section{DISCUSSION}

This study examines the effects of the use of a conversational model, opportunities for reflection, sex, and combinations of these variables on interpersonal skills development with the help of a computer-based tool. Subjects, assigned to groups of two in four treatment groups, received interpersonal skills training: information, (video) examples, practice with computer-based role-playing, and feedback. Each training included the presence $\left(\mathrm{C}^{+}\right)$or absence $\left(\mathrm{C}^{-}\right)$of a conversational model and opportunities for reflection (high, $\mathbf{R}^{+}$, or low, $\mathbf{R}^{-}$).

Results for learning outcomes indicated that knowledge acquisition is influenced by a combination of the use of a conversational model and opportunities for reflection. The $\mathrm{C}^{+}$groups performed better on the knowledge test when they were provided with high opportunities for reflection rather than low opportunities. For the $\mathrm{C}^{-}$groups, there were no apparent differences in knowledge acquisition when the high and low opportunities for reflection were compared.

Providing high opportunities for reflection to groups that received the conversational model may have guided students to reflect on and remember the availability of relevant information in memory they already knew and relate this information to performance of the skill. This attention to information that is relevant to skills acquisition, in combination with reflection (active chaining, careful ordering of interconnected ideas), should result in knowledge that is deeper rooted and more flexible than knowledge obtained otherwise. Providing high or low opportunities for reflection to groups that received no conversational model did not lead to any apparent 
difference. A possible explanation for this finding may be that the reflections are too diverse, loose, and ineffective without guidance that focuses the attention of the students on the availability of relevant information.

This finding results in a suggestion for refinement of the hypotheses about influence of the opportunities for reflection on the learning outcomes. It is expected that, only in combination with the use of a conversational model, would the $\mathbf{R}^{+}$groups show more effective interpersonal skill acquisition, knowledge acquisition, and more complete understanding of the skill than the $\mathbf{R}^{-}$groups. This refinement has consequences for the training principle reflection opportunities: instruction should only offer opportunities for reflection in combination with the use of a conversational model that offers a general heuristic that reflections may refer to.

The present results also indicate that the use of a conversational model only affects the learning outcomes. $\mathrm{C}^{+}$groups performed significantly better than $\mathrm{C}^{-}$groups on a computer-based role-play and on the knowledge test. This finding supports one of the hypotheses of this study: it was expected that the $\mathrm{C}^{+}$groups would show more effective interpersonal skill acquisition, knowledge acquisition, and a more complete understanding of the skill (better tests results) than the $\mathrm{C}^{-}$groups. A conversational model accommodates students' need for "guidance", for "direction" in solving interpersonal problems. The guidance may direct students' attention to relevant information in memory they already know and which is highly integrated with knowledge that already exists. This information can be helpful to the performance of the skill. These results also provide support for researchers who have suggested that it is helpful to present heuristics to students (Mettes et al., 1981; Schoenfeld, 1979; Van Merriënboer et al., 1992) and for researchers who are concerned with giving guidance in problemsolving situations (Redding, 1990). Guidance seems to be an effective way to turn a "poor" novice problem solver into a "good" novice problem solver, thereby facilitating the development of expertise. The results also provided support for real-life training and education where numerous conversational models for different conversation types do yield good results (DeBest \& Boertien, 1990).

It is also likely that sex affects the learning outcomes. Females performed significantly better than males in a computer-based role-play and on the knowledge test. Research findings suggest that males and females differ in their communication styles (Coates, 1993; Cowan, Wilcox, \& Nykodym, 1990; Penley, Alexander, Jernigan, \& Henwood, 1991; Smith \& DeWine, 1991; Tannen, 1994) which indicates that females are more competent on some communication items (Luketich, Colliver, \& Galofré, 1992; Stillman, Regan, Swanson, \& Haley, 1990). The sex of the students in the current study may have influenced their skill acquisition. 
In the present study, opportunities for reflection during role-playing were realized in several ways: students can revise each message, determine when the next message is exchanged, and can read back the dialog, the descriptions of the social situation, and the description of the role. $\mathbf{R}^{+}$groups were given time to think consciously about what was taking place and modify actions virtually instantaneously. Here reflection refers to "reflection-in-action" (Schön, 1983, 1987); simultaneously reflecting and doing. Another approach of reflection is that thoughtful and critically questioning novices will develop expertise (Korthagen, 1985, 1992; Korthagen \& Verkuyl, 1987). This operationalization was not made in this study. In the literature, there is a considerable difference in definition and interpretation of reflection, debriefing, and evaluative feedback in which reflections are made. Further, there is no reported research that specifically examines reflective thought in relation to skills improvement (Gipe \& Richards, 1992).

In this study it has been chosen to manipulate opportunities for reflection during role-playing and to make no combination with potential opportunities for reflection after each role-play. An argument for this choice is that, with the help of a computer-based tool, a unique possibility is offered to promote reflection during the role-play. Other arguments are standardization and better experimental control.

In addition to learning outcomes, the training programs have influence on learning processes. The learning processes were split up for activity level and time spent on different activities. Results for activity level indicated that the average number of messages sent was influenced by a combination of the use of a conversational model and opportunities for reflection. $\mathbf{R}^{-}$groups sent more messages when the conversational model was absent rather than present. A possible explanation may be due to the operationalization of opportunities for reflection and the guidance given by the conversational model. $\mathrm{R}^{-}$groups were given $1 \mathrm{~min}$ to formulate an answer. The formulated answers had to be short because of this time restriction. $\mathbf{R}^{-}$groups needed to send more messages to "tell" the same content as $\mathrm{R}^{+}$groups. The $\mathrm{C}^{-}$groups sent more messages than the $\mathrm{C}^{+}$groups because of lack of guidance. The $\mathrm{C}^{-}$ groups had to solve interpersonal problems by trial-and-error which meant more attempts and, thus, more messages.

The present results for activity level also indicate that the $\mathrm{C}^{+} \mathrm{R}^{+}$group consulted the description of the social situation and the description of the role significantly more than the $\mathrm{C}^{-} \mathbf{R}^{+}$group. As stated before, the use of the conversational model gives guidance to solve interpersonal problems. This guidance focuses the students on relevant aspects of the interpersonal problem. These relevant aspects are mentioned, for example, in the description of the social situation and the description of the role. The students consulted these descriptions to find these relevant aspects. Students 
who had no conversational model at their disposal and, thus, no guidance, lost focus on the relevant aspects and consulted these descriptions less to find relevant aspects.

With regard to the time spent on activities, results indicated that $\mathbf{R}^{+}$ groups spent more time on performance in computer-based role-playing than $\mathbf{R}^{-}$groups. This may have occurred because students make reflections during role-playing which are time-consuming. Results also indicate that the $\mathrm{C}^{+}$groups, compared with $\mathrm{C}^{-}$groups, spent much more time on performance in computer-based role-playing when they were provided with high rather than low opportunities for reflection. This finding was not expected because students who worked without a conversational model or guidance were left to trial-and-error which is time-consuming. A possible explanation of the use of more time by the $\mathrm{C}^{+}$groups may be motivational factors. The $\mathrm{C}^{+}$groups were more engaged in the tasks than $\mathrm{C}^{-}$groups. $\mathrm{C}^{+}$ groups made more corrections and deleted more text to improve their messages than $\mathrm{C}^{-}$groups. This was time-consuming. Unfortunately, the registration of the number of corrections in the logfile was not easy to implement and so not done.

In accordance with more consultation of the description of the social situation and the description of the role by the $\mathrm{C}^{+} \mathrm{R}^{+}$group, the results indicated that this group also spent significantly more time on consultation than the $\mathrm{C}^{-} \mathrm{R}^{+}$group.

Turning to the appreciation of the quality of the training programs, results suggest that, in general, students judged the quality of the training programs as equally effective, useful, and manageable.

The current study has some limitations that should be addressed. First, the assignment to groups of two heightened the experimental loss. If a student did not show, another could not participate. To overcome this problem, substitute students were brought into action. This was not always possible, so lots were drawn which student had to leave the experiment. Experimental loss complicated the stratified random sampling procedure and led to haphazard cell frequencies and gender disproportionality in the $\mathrm{C}^{-} \mathrm{R}^{-}$cell. Second, the number of corrections made by the students in the high reflection opportunities groups were not registered. This registration may give more insight into the time spent on different activities and the kind of corrections made in the learning process. Third, another operationalization of opportunities for reflection during and after computer-based role-playing may have further impact than those used in this study. Fourth, the role of the antagonist is not taken into consideration. The role of antagonist is interpreted as a constant, whereas this need not be the case. Fifth, the actual research was carried out in an environment that was "unnatural" in 
that it attempted to control as many variables as possible. To test the reliability of the research, other studies should be done in a more "natural" environment, in real-life training, using the same program as a graduate leadin to conventional role-playing with other participants and actors. The different combinations of training strategies (computer-based role-playing, role-playing with other participants and role-playing with actors) need to be studied. Also, the relation between the effect of different training strategies and the level of expertise by the trainees needs to be explored.

Future studies are needed to explore other possible applications of the program. As far as possible to judge now, the program can be used in a wide variety of ways depending on how the characters are represented graphically, how the context of their exchange is introduced, and how roles are allocated to users. The program could be used in the training of other professionals involving development of interpersonal skills. Thus, the program cannot be used for skills to deal with interactive processes involved in an interaction larger than a dyadic one (two persons). Examples of professional training are doctor and nursing education (a trainee talking to a very ill patient) and vocational training of novice lawyers (a lawyer has to tell bad news to his client). Applications of the program also seem possible for individual populations who have failed to develop adequate communication skills for several reasons (e.g., in a social skills training program for psychiatric clients). A precondition is a sufficient level of reading and writing skills.

The issue of measuring interpersonal skills (Smit, 1995) and the lack of assessment instruments have not been addressed in this study. Future studies could explore ways to use computer-based role-playing for skills assessment; for instance, it offers the possibility to capture individual contributions and learning processes. Research is also needed to examine reflective thought in relation to skills development and improvement (Gipe \& Richards, 1992).

To leave no doubt, there is a reasonable amount of work still to be done for those who would like to use technology to assist in realizing effective interpersonal skills development. This study has shown that technology can be used to assist in realizing effective gradual lead into interpersonal skills learning and instruction. Results substantiate the notion that computerbased role-playing with the use of a conversational model in combination with opportunities for reflections may improve interpersonal skills training for novices.

Acknowledgments - Special thanks go to Rina Baltjes for her assistance as experimenter and Ap te Winkel, for his assessment of the printouts of the dialogs. I gratefully acknowledge the comments and suggestions of Martijn Berger, Sanne Dijkstra, Jeroen van Merriënboer, Hans van der Meij, and two anonymous reviewers on this research and earlier drafts of this article. All materials (and software) mentioned in this article are available from the author. Please write. 


\section{REFERENCES}

L'Abate, L., \& Milan, M. A. (Eds.). (1985). Handbook of social skill training and research. New York: John Wiley \& Sons.

Alliger, G., Serbell, C., \& Vadas, J. (1989). Computer-based simulation for soft skills training. The Videodisc Monitor, 7, 24-29.

Alpert, D. (1986). A preliminary investigation of computer-enhanced counselor training. Computers in Human Behavior, 2, 63-70.

Baker, S. B., \& Daniels, T. G. (1989). A meta-analytic review of research on the effects of Ivey's microcounseling program. Journal of Counseling Psychology, 36, 213-222.

Boud, D., \& Walker, D. (1991, July). In the midst of experience: Developing a model to aid learners and facilitators. Paper presented at the National Conference of Experiential Learning, University of Surrey, England.

Campbell, J. O., Lison, C. A., Borsook, T. K., Hoover, J. A., \& Amold, P. H. (1995). Using computer and video technologies to develop interpersonal skills. Computers in Human Behavior, 11, 223-239.

Carrol, J. M., \& Rosson, M. B. (1984). Beyond MIPS: Performance is not quality. Byte, 2, $168-172$.

Coates, J. (1993). Women, men and language: A sociolinguistic account of differences in language. London: Longman.

Cowan, K. M., Wilcox, J. R., \& Nykodym, N. (1990). A comparative analysis of female communication style as a function of organizational level. Communications, 15(3), 291-309.

Cronin, M. W., \& Cronin, K. A. (1992). Recent empirical studies of the pedagogical effects of interactive video instruction in "soft skill" areas. Journal of Computing in Higher Education, 3(2), 53-85.

DeBest, K., \& Boertien, A. H. (1990). Communicatie-technieken [Communication techniques]. Groningen: Wolters-Noordhoff.

Dewey, J. (1933). How we think: A restatement of the relation of reflective thinking to the educative process. Boston: D. C. Heath.

Ericsson, K. A., \& Simon, H. A. (1980). Verbal reports as data. Psychological Review, 87, 215-251.

Ericsson, K. A., \& Simon, H. A. (1984). Protocol analysis. Verbal reports as data. Cambridge, MA: MIT Press.

Fletcher, J. D. (1990). Effectiveness and cost of interactive videodisc instruction in defense training and education (IDA paper P-2372). Alexandria, VA: Institute for Defense Analyses.

Georges, J. C. (1989). The hard reality of soft-skills training. Personnel Journal, 4, 41-45.

Gipe, J. P., \& Richards, J. C. (1992). Reflective thinking and growth in novices' teaching abilities. Journal of Educational Research, 86, 52-57.

Goldstein, A. P. (1973). Structured learning therapy: Toward a psychotherapy for the poor. New York: Academic Press.

Goldstein, A. P. (1981). Psychological skill training: The structured learning technique. New York: Pergamon Press.

Hargie, O. (1986). A handbook of communication skills. London and Sydney: Croom Helm.

Hatton, N., \& Smith, D. (1995). Reflection in teacher education: Towards definition and implementation. Teaching and Teacher Education, 11, 33-49.

Hollin, C. R., \& Trower, P. (Eds.). (1986). Handbook of social skill training (Vols. 1 \& 2). Oxford, England: Pergamon Press.

Holsbrink-Engels, G. A. (1994). Visions of Dutch corporate trainers on role playing. In D. Saunders, F. Percival, \& R. Armstrong (Eds.), The 1994 simulation and gaming yearbook (pp. 96-110). London: Kogan Page.

Holsbrink-Engels, G. A. (in press). Computer-based role playing for interpersonal skills training. Simulation and gaming. Newbury Park, CA: Sage Publications. 
Ivey, A. E. (1971). Microcounseling: Innovations in interviewing training. Springfield, IL: Charles C. Thomas.

Ivey, A. E., \& Authier, J. (1978). Microcounseling: Innovations in interviewing, counseling, psychotherapy and psychoeducation. Springfield, IL: Charles C. Thomas.

Joyce, B. R., \& Weil, M. (1980). Models of teaching. Englewood Cliffs, NJ: Prentice-Hall.

Kass, A., Burke, R., Blevis, E., \& Williamson, M. (1993-1994). Constructing learning environments for complex social skills. The Journal of Learning Sciences, 3, 387-427.

Kessels, J., \& Smit, C. (1990). Het rollenspel? Ik kijk wel [Role playing? I watch]. Opleiding en Ontwikkeling, 4, 9-15.

Korthagen, F. A. J. (1985). Reflective teaching and preservice teacher education in the Netherlands. Journals of Teacher Education, 36, 11-15.

Korthagen, F. A. J. (1992). Techniques for stimulating reflection in teacher education seminars. Teaching and Teacher Education, 8, 265-274.

Korthagen, F. A. J., \& Verkuyl, H. S. (1987, April). Supply and demand: Towards differentiation in teacher education, based on differences in learning orientations. Paper presented at the annual meeting of American Educational Research Association, Washington, DC.

Kraan, H. F., \& Crijnen, A. A. M. (1987). The Maastricht History-Taking and Advice Checklist: Studies of instrumental utility. Amsterdam: Lundbeck.

Kremer-Hayon, L. (1988). Reflection and professional knowledge - A conceptual framework. ED 296971.

Luketich, G. F., Colliver, J. A., \& Galofré, A. (1992). Two studies of the effects of gender within single case simulated by male and by a female standardized patient in a multiplestations examination. In R. M. Harden, I. R. Hart \& H. Mulholland. Approaches to the assessment of clinical competence (part 1) (conference book). Dundee, Scotland: Centre for Medical Education.

Marshall, E. K., \& Kurtz, P. D. (Eds.). (1982). Interpersonal helping skills. San Francisco, CA: Jossey-Bass.

Martin, A., Jones, E., \& Hearn, G. (1994). Comparing interactive videodisc instruction with traditional methods of social skills training. Educational and Training Technology International, 31, 187-195.

Mettes, C. T. W., Pilot, A., \& Roossink, H. J. (1981). Linking factual knowledge and procedural knowledge in solving science problem: A case study in a thermodynamics course. Instructional Science, 10, 333-361.

Nijkerk, K. J. (1988). Het rollenspel. In J. W. M. Kessels \& C. A. Smit (Eds.), Handboek opleiders in organisaties. Deventer, The Netherlands: Kluwer Bedrijfswetenschappen.

Nisbett, R. E., \& DeCamp Wilson, T. (1977). Telling more than we can know: Verbal reports on mental processes. Psychological Review, 84, 231-259.

Orlansky, J., \& String, J. (1977). Cost effectiveness of computer-based instruction in military training (IDA paper P-1375). Alexandria, VA: Institute for Defense Analyses.

Penley, L. E., Alexander, E. R., Jernigan, I. E., \& Henwood, C. I. (1991). Communication abilities of managers: The relationship to performance. Journal of Management, 17(1), $57-76$.

Redding, R. (1990). Metacognitive instruction: Trainers teaching thinking skills. Performance Impravement Quarterly, 3(1), 27-41.

Schoenfeld, A. H. (1979). Can heuristics be taught? In J. Lochhead \& J. Clement (Eds.), Cognitive process instruction (pp. 315-338). Philadelphia, PA: Franklin Institute Press.

Schön, D. (1983). The reflective practitioner: How professionals think in action. New York: Basic Books.

Schön, D. (1987). Educating the reflective practitioner: Toward a new design for teaching and learning in the professions. San Francisco, CA: Jossey Bass.

Schroeder, J. E., Dyer, F. N., Czerny, P., Youngling, E. W., \& Gillotti, D. P. (1986). Videodisc interpersonal skills training and assessment (VISTA): Overview and findings: Vol. 1. Final report (Report No. ARI-TR-703). Fort Benning, GA: Litton Mellonics Systems Development Div. (ERIC Document Reproduction Service No. ED 274 329) 
Smit, G. N. (1995). De beoordeling van professionele vaardigheden, constructie en evaluatie van rollenspel-, video- en schriftelijke toetsen [Assessment of professional conversation skills]. Baarn, The Netherlands: H. Nelissen.

Smith, G. L., \& Dewine, S. (1991). Perceptions of subordinates and requests for support. Are males and females perceived differently when seeking help? Group and Organization Studies, 16(4), 408-427.

Sparks-Langer, G., \& Colton, A. (1991, March). Synthesis of research on teacher's reflective thinking. Educational Leadership, pp. 37-44.

Stillman, P. L., Regan, M. B., Swanson, D. B., \& Haley, H. L. (1990). Does gender affect clinical skills as measured by multiple station examinations using standardized patients? In I. R. Hart \& R. M. Harden (Eds.), More developments in assessing clinical competence (conference book). Montreal, Canada: Can-Heal Publications.

Tannen, D. (1994). Talking from 9 to 5. New York: Morrow.

Van Ments, M. (1989). The effective use of role play: A handbook for teachers and trainers. London: Kogan Page.

Van Merriënboer, J. J. G., Jelsma, O., \& Paas, F. G. W. C. (1992). Training for reflective expertise: A four-component instructional design model for complex cognitive skills. Educational Technology, Research and Development, 2, 23-43.

Waxman, H., Freiberg, H., Vaughan, J., \& Weil, M. (1988). Images of reflection in teacher education. Reston, VA: Association of Teacher Educators.

Wheatley, G. H. (1992). The role of reflection in mathematics learning. Educational Studies in Mathematics, 23, 529-541.

Winograd, T., \& Flores, F. (1986). Understanding computers and cognition. Norwood, NJ: Ablex. 